\title{
Do Tanzanian Undergraduate Students Choose or Hunt for their Degree Programmes?
}

\author{
Jaqueline Amani ${ }^{1}$ \\ ${ }^{1}$ Faculty of Education, Mkwawa University College of Education, 2513, Iringa, Tanzania \\ Correspondence: Jaqueline Amani, Faculty of Education, Mkwawa University College of Education, 2513, Iringa, \\ Tanzania
}

Received: January 31, 2016

Accepted: February 26, 2016

Online Published: March 2, 2016

doi:10.5430/ijhe.v5n2p74

URL: http://dx.doi.org/10.5430/ijhe.v5n2p74

\begin{abstract}
This article sets out to determine the association between the reasons why university students in Tanzania select their fields of study and intention to join their respective professions upon completion of their studies. A mixed methods research approach was adopted to study a random sample of 1043 undergraduate students $($ Male $=61 \%$, Female $=39 \%$ ) drawn from four universities. The study found that determinants of career choice and intentions differed significantly with fields of study. Students' intentions to join their prospective careers were more associated with intrinsic than extrinsic factors. Furthermore, students whose degree programmes were their first choices were more likely to re-choose if asked to do so and join their prospective careers than those who joined by chance. The study concludes that when students choose their degree programmes with enough knowledge and interest, they are more likely to enjoy and be committed to the chosen fields of study, hence, satisfaction in their future career.
\end{abstract}

Keywords: Career choice, Intrinsic and extrinsic factors, Social cognitive career theory, Undergraduate students, Tanzania

\section{Background}

This article holds the position that at one time people needed to decide on a suitable career to pursue in life. It is evident that individuals possess unique characteristics, values, needs and personalities, which result in different career aspirations and expectations (Mubiana, 2010; Datu, 2012). However, for them to pursue the right career, they need to make a wise and careful choice. It is obvious that individuals in any profession - be it engineering, teaching, law, accountancy or medicine - are informed by several factors when it comes to career choices. This means that people need to have reasons for preferring one career to another. The reasons should be accompanied by, among others, enough occupational information relating to the respective career (Kidd, 2009). Occupational information would not be possible without adequate career search and exploration that make the process not only complex but also dynamic. The complexity and dynamic nature of career decision making is evidenced in the following quote by Isaacson (1985) who asserts:

......A college graduate in mathematics and engineering at the age of eighteen first accepted a job as a civil engineer for a railroad company, but the company failed before he reported to work. He then worked for almost a year in a rolling mill. Next, he obtained an elementary teaching position, later advancing to a high school teaching assignment. At the urging of a friend he began to read law, preparing for the bar examination that he successfully passed. Six years later he joined the faculty of a local university law school but was an unsuccessful candidate for mayor of Boston. He subsequently moved to the Midwest, becoming a professor at an agricultural and applied science institution (p.29).

The above remark is based on the experience of Frank Parsons, the prominent pioneer of occupational choice and counselling (Herr \& Crammer, 1992). Parson's experience is a classic example of how career choice is complex but dynamic. The interpretation of Parsons's occupational experience is that people face difficulties in career decision making. This has resulted into the formulation of principles which are worth considering before one chooses a career. Firstly, "it is better to choose a career rather than merely hunt for it. Secondly, no-one should choose a career without a thorough and honest self-analysis and guidance. Thirdly, young people should survey the field of vocations, and not simply drop into one by accident (Parsons, 1909 as cited in Isaacson, 1985, p.29). 
There is a considerable difference between an individual who chooses a career and one who hunts for it or drops into it by accident. The difference is that choosing a career from various career lists requires consideration of many factors, which make individuals to value one career over another. This implies that a thorough survey on various career options against their values has to be done so that a sound choice is made. However, if an individual fails to make a wise choice for various reasons, then hunting becomes an alternative way. In practice, the hunted career is not an alternative solution, because an individual may not be interested with it (Herr \& Crammer, 1992). In other words, the hunted career may be seen as simple and pleasant solution, but its future implications might be hard to take. This is due to the fact that a chosen career has to fulfil certain needs and expectations which are closely related to one's interests and personality. When it fails, it will mean a gap between one's career expectation, needs and values; hence, job dissatisfaction is inevitable. This interpretation supports Akomolafe's (2003) idea that true joy, happiness and satisfaction are partly linked to the right choice of career. Thus, in order to have job satisfaction and a sense of security, choosing the right career is very important for every job seeker.

Worldwide, university students are in transition to the world of work. For them, a careful choice of their career is perhaps more important than any other groups of students as they need to reflect on their chosen majors, interests, ability and consider what is available in the world of work. Surprisingly, studies on the career choice attest that many undergraduate students choose their prospective careers as a last resort (Bennell, 2004; Nwalo \& Issa, 2008). As a result, the majority of students are not suited for their careers, and, as such, they usually find themselves in careers that do not satisfy their needs and interests (Nwalo \& Issa, 2008).This implies that the majority of graduates will end up working in careers they were not trained for. A few graduates who decide to join will probably not stay long. Consequently, their work performance, and in turn, national development will also be affected.

The available studies have shown that for students to join their careers a careful analysis of what has influenced their choices is imperative (Wang \& Fwu, 2001; Yu, 2011). This implies that there is a close relationship between the reasons for an individual's career choice and his or her future decision to join it. Empirical studies in Tanzania focused on determinants of career choice (Cosmas, 2010; Mhenga, 2011; Mbilinyi, 2012) but paid less attention to the relationship between what is behind the choice and students' decisions to join their prospective careers. Nevertheless, these studies targeted at secondary education level leaving very little known among university students who are in the transition from colleges to the world of work. Therefore, the current study addresses three interrelated objectives. First, it assesses the differences in career choice determinants across various fields of study. Second, it determines the association between career choice factors and students' intentions to join their chosen careers upon completion of their studies. Third, it determines the association between students' intentions to join their careers with, the fields they are pursuing; the level of satisfaction with their chosen field; and whether or not the field of study was their first choice. This information will not only be used by students for raising awareness about how their choices influence the intention to join their profession in future and the world of work, but also by the government, graduates and prospective employers to receive feedback on what students value most when choosing and joining their careers.

\section{What influences Our Career Decisions? Theoretical Perspectives}

In attempt to address career development needs of a diverse population a plenty of career theories have been developed. The current study adopts a social cognitive career theory (SCCT) which is one among the most prominent social cognitive career theories championed by Lent, Hackett and Brown in 1994. SCCT is derived from Alfred Bandura's (1986) social cognitive theory to explore how career choices are made and turned into actions (Lent et al., 1994). The SCCT builds on the assumption that both cognitive and contextual factors play a key role in explaining one's career decision making. The key theoretical constructs of SCCT are self-efficacy, personal goal/intention, outcome expectations and contextual supports and barriers (Lent et al., 1994). The theory is grounded on the fact that an individual's choice of a career is highly dependent on self-efficacy beliefs (Lent et al., 1994). Betz and Hackett (2006) claim that almost every individual lacks confidence in the ability to produce the right behaviour in different contexts, which may result in avoiding certain behaviours or not being motivated to cultivate career-related behaviours (Betz \& Hackett, 2006). Another construct in the SCCT is goal/intention. According to Lent et al. (1994) goals are seen as primary antecedents of behaviour. The behaviour is very likely to be produced and/or sustained based on the previous intentions or goals. On top of that, self-interest is another variable mentioned in the theory. SCCT assumes that individuals are more likely to engage in planning their career goals and ultimately make a choice on the basis of their personal interest in a particular career.

Moreover, outcome expectation is another important factor influencing career choice in this theory. In the context of career choice, outcome expectation may be viewed as people's beliefs concerning the extent to which they will satisfy their core values if they pursue a particular career path. This is very important because when there is a 
mismatch between what a person values and what that particular career offers, then it will more likely affect personal interest and goals. The SCCT also puts forward various contextual factors which might motivate or affect individuals' career choices. These include: socio-economic status (parental income), job opportunities, social policies and procedures for selecting trainees (Lent \& Brown, 2006). All these factors in a one way or another might provide support for or barriers to attaining one's career choice. This study draws on the SCCT to study the association between the factors that account for career choices of university students and their decisions to join their careers when they complete their studies. Although the SCCT informs the study on how career choices are made and the extent to which choices are turned into action, it is silent on the fact that some contextual factors might play a dual role in influencing both the choice and intentions. For example, family, employment opportunities and self-interest are likely to influence both the choice of career, intentions to join and stay with it in future, while lack of academic qualifications may either promote or deter both career choice and intention to join the chosen career in future.

\section{Material and Methods}

A concurrent mixed methods design was adopted for this study. This is a well-known design in which the researcher collects and analyses both quantitative and qualitative stances in a single phase of study and merges the two sets of results to provide an overall interpretation (Creswell, 2012). The concurrent design helped the researcher to obtain different but complementary data that gave this study a better understanding of the problem. Creswell (2012) asserts that the concurrent design is used when a researcher wants to triangulate the methods by directly comparing and contrasting quantitative statistical results with qualitative findings for corroboration and validation purposes. Thus, two sets of data from focus group interviews and questionnaires were collected concurrently. The data were then analysed independently using various analytical procedures. The results were presented and compared for interpretation.

\subsection{Participants and Selection Procedures}

Participants in this study were $(\mathrm{N}=1043)$ first year and finalist undergraduate students who majored in the fields of teaching, engineering, business studies and law. The participants for this study were recruited from four universities located in Dar es Salaam, Iringa, Dodoma and Morogoro regions. The universities were: University of Dar es Salaam, University of Dodoma, Iringa University and Muslim University of Morogoro. The sample size for the survey in each university was determined by Cohen's statistical table and drawn from a computer table of random numbers. On the hand, the researcher used focus group discussion as a method for qualitative data collection. This was informed by the need to appreciate the way in which students perceive their own reality through their fellow's thoughts and how their thoughts concur with or contradict those of others. Out of 1043 students, a total of 14 focus groups of between 6-8 participants were formed for discussion. The members for group discussion were purposefully selected, whereby the year of study, fields of study, number of participants per group and sex were considered to be key criteria. Participants were informed on the objective of this study and an informed consent was sought before their participation.

\subsection{Instruments and Analysis Plan}

A questionnaire was designed to assess participants' demographic information (age, sex \& year of study), reasons for choice of their fields, and intentions to join prospective profession upon completion of their studies. Participants were instructed to respond on a likert-type items ranging from 1(strongly disagree) to 4 (strongly agree) with higher scores indicating strong career intentions. Also they were requested to put a tick in a box written yes or no (dichotomous) against seven factors which had an influence on their decision to pursuing degrees in law, education, engineering and business. Overall, 518 (49.7\%) of participants were first year, while 525(50.3) were finalist students. The mean age for participants was $24.9(\mathrm{SD}=4.4)$. Deductive thematic analysis was used to analyse the qualitative data, while the quantitative data were analysed using SPSS version 20. Both descriptive and inferential statistics were computed for making statistical inferences. In particular, chi square tests were run to determine the association between categorical scores of reasons for choosing a career and intention to join the chosen career in future.

\section{Results}

\subsection{Difference in Career Choice Factors by Students' Fields of Study}

The study examined whether career choice factors differed by students' fields of study. Quantitative and qualitative data were collected for triangulation purposes (see Table 1). 
Table 1. Differences in Career Choice Factors by Students' Fields of Study

\begin{tabular}{|c|c|c|c|c|c|c|c|c|c|}
\hline \multirow[t]{2}{*}{ Career Choice Factor } & & \multicolumn{4}{|c|}{ Fields of Study } & \multirow[t]{2}{*}{$\chi^{2}$} & \multirow[t]{2}{*}{$d f$} & \multirow[t]{2}{*}{$P$} & \multirow[t]{2}{*}{ Cramer's v } \\
\hline & & $\begin{array}{l}\text { Education } \\
(\mathrm{N}=678)\end{array}$ & $\begin{array}{c}\text { Law } \\
(\mathrm{N}=115)\end{array}$ & $\begin{array}{l}\text { Business } \\
(\mathrm{N}=159)\end{array}$ & $\begin{array}{l}\text { Engineering } \\
(\mathrm{N}=91)\end{array}$ & & & & \\
\hline \multirow[t]{2}{*}{ Personal Interest } & $\mathrm{N}$ & 461 & 91 & 125 & 81 & 48.46 & 3 & .000 & .21 \\
\hline & $\%$ & 61.4 & 79.1 & 81.2 & 89 & & & & \\
\hline \multirow[t]{2}{*}{ Family influence } & $\mathrm{N}$ & 504 & 64 & 100 & 59 & 20.90 & 3 & .000 & .14 \\
\hline & $\%$ & 74.3 & 55.7 & 64.9 & 64.9 & & & & \\
\hline \multirow[t]{2}{*}{ Poor academic performance } & $\mathrm{N}$ & 271 & 14 & 18 & 19 & 75.75 & 3 & .000 & .27 \\
\hline & $\%$ & 40 & 12.2 & 11.7 & 20.9 & & & & \\
\hline \multirow[t]{2}{*}{ Secure Loan } & $\mathrm{N}$ & 470 & 44 & 63 & 56 & 94.61 & 3 & .002 & .30 \\
\hline & $\%$ & 69.7 & 26.9 & 40.9 & 61.5 & & & & \\
\hline \multirow[t]{2}{*}{ Easy to get employment } & $\mathrm{N}$ & 521 & 67 & 84 & 51 & 48.88 & 3 & .001 & .21 \\
\hline & $\%$ & 76.9 & 57.8 & 54.5 & 56 & & & & \\
\hline \multirow[t]{2}{*}{ Self-employment } & $\mathrm{N}$ & 143 & 53 & 98 & 43 & 127.06 & 3 & .000 & .35 \\
\hline & $\%$ & 21.1 & 46.1 & 63.3 & 47.3 & & & & \\
\hline \multirow[t]{2}{*}{ Job prestige } & $\mathrm{N}$ & 147 & 78 & 78 & 57 & 71.03 & 3 & .000 & .26 \\
\hline & $\%$ & 25.7 & 67.2 & 50 & 62.6 & & & & \\
\hline
\end{tabular}

Note: $p$ is significant at.01

Table 1 presents variations in career choice factors by fields of study. The strengths of association indicated by Cramer's value were strongly supporting the fact that there is a significant relationship between career choice factors and the chosen fields. The study found a statistically differences between various factors influencing students' career choice across fields of study as follows: personal interest $\chi^{2}=(3,727)=48.46, p=.000$. The analysis indicates that a higher proportion of students in the field of engineering were more influenced by self-interest than those in other fields. This is also supported by the content analysis of focus group interviews. One of the students pursuing engineering remarked:

"Since the time I was young, I have been enjoying to play with machines. I reached a point where my father called me 'my engineer...my engineer come and help me with these...' so I was very interested in studying engineering right from the very beginning."

Moreover, Table 1 indicates that a greater number of students in the field of education than students in the remaining fields reported that family influence was one of the main reasons for the choice of their career $\chi^{2}={ }_{(3,727)}=20.90$, $p=.000$. This is also in line with the content analysis as expressed by a student teacher who asserted:

"My parents made a great contribution to my career choice. Both my mother and father are teachers and so also is my sister. So together they influenced me to become a teacher. In short, I can say we are a family of teachers".

Additionally, ease to get employment upon graduation was revealed as another influence of career choice among student teachers $\chi 2={ }_{(3,723)}=44.88, p=.001$, while self-employment was found to be a more important factor for business students than those in other fields $\chi 2={ }_{(3,335)}=127.06, p=.000$. Furthermore, higher proportion of students majoring in education were more influenced by their poor academic performance $\chi 2={ }_{(3,423)}=75.74, p=.000$ and loan availability $\chi^{2}{ }_{(3,633)}=94.63, p=.002$ than students in other fields. One student teacher had this to say:

"Yeah! Sometimes we are here because we did not qualify to be somewhere else. I studied education because I failed mathematics. I also had lower principal passes in economics and geography and the cut-off point for Bachelor of Commerce was high. Therefore, I was automatically disqualified from doing the programme. It hurts but there was no way out. I had to 
be enrolled in BA with Education. I liked business studies unfortunately the conditions did not allow".

Lastly, students in the field of law and engineering were more influenced by the prestige of the career itself $\chi 2={ }_{(3,386)}$ $=71.03, p=.000$ than students in other fields. This was an indication that the profile of the professions motivated their career choice.

\subsection{Relationship between Career Choice Factors and Students' Intentions to Join and remain in their Prospective Career}

Despite the established variations in career choice factors by students' fields of study, the study further examined the relationship between factors which made students choose careers degree programmes and intention to join them their prospective careers in future. A Chi-square test was run to determine the association between career intention scores and frequencies observed in career choice factors. The results showed a statistically significant relationship between various career choice factors and career intentions as follows. Interest as a career choice factor had a significant relationship with students' decisions to join their careers, $\chi^{2}=9.04, d f=1, p=.003$, phi $=.09$ implying that many students who had interest in their chosen fields intended to join their professions in future than those who had no interest. Also, family influence was significantly related to students' intention to join their prospective careers upon graduation $\chi 2=19.09, d f=1, p=.000$, phi=.13. This indicates that the role of family in influencing students' future career destinations is very important. Additionally, the employment phobia was a very significant factor which influenced students' decision to join their future careers $\chi^{2}=67.26, d f=1, p=.005$, $p h i=.25$. Lastly, job prestige was another factor influencing students' decision to join their careers $\chi 2=7.34, d f=1, p=.007$, phi=.08. Generally, what made someone choose a career significantly influenced his or her intention to enter it upon graduation. That is, whether an individual ended up joining his or her chosen career was partly determined by what made him or her choose to study the respective field.

Furthermore, when the possibility of students choosing the same degree programmes when given another opportunity was analysed, the results showed that the overwhelming majority of students doing business studies, $89.9 \%$, would choose the same programme if asked to do so, followed by engineering, $84.4 \%$, law, $75 \%$, and education, $65.9 \%$. Consistently, content analysis showed that most student teachers were more likely to change their degree programme if they had an opportunity to do so. For example, one student teacher holds that:

"This has been my cry for so long...First of all I want to make this clear: I am a teacher by accident not by choice. TCU gave seven choices, but I chose education, the $7^{\text {th }}$ choice, just to fill the space, but I never wanted to be a teacher. I liked things to do with money you know... (laughing)...money is everything but my grades, especially ' $\mathrm{F}$ ' in Mathematics, forced me to do what I am doing right now. I hate teaching, and let me tell you the truth, I am a $3^{\text {rd }}$ year student (finalist) but I am planning to register for another degree. I don't really think that a BA.Ed is worth much. You know what, I feel a gap somewhere and I am thinking of starting another degree at Makerere University, these are my plans."

While student teachers were eager to change their fields their fellow in engineering had different feelings:

"Even if I were to choose today or 5 years later I would choose the same programme. I have very strong reasons for doing engineering. In fact, I will not be doing justice to both myself and my profession if I stay here for 4 years studying engineering and then someone finds me pursuing another degree for a different profession or working as a bank teller somewhere."

This was one of the interesting and perhaps exciting findings in this research that students who were intrinsically motivated to choose their careers were very likely to choose the same careers in future, and so the possibility of remaining in their careers was high. Comparative analysis revealed that students in the education field were less likely than their fellows in terms of their ambitions to choose the same fields if they had chance to do so. This was an indication that they felt they were in the wrong place and so if they had chance they would change to a different degree programme.

\subsection{Differences in Career Intentions by Students' Fields of Study and Level of Satisfaction}

A chi-square test was conducted to assess the variation in intentions to join the prospective careers of university students in the four fields of study. The results showed statistically significant difference $\chi^{2}{ }_{(3,1043)}=73.40, p=.000$, with more students from engineering and business studies intending to join their careers than students taking law and education. Figure 1 shows the variations in percentages by fields of study. 


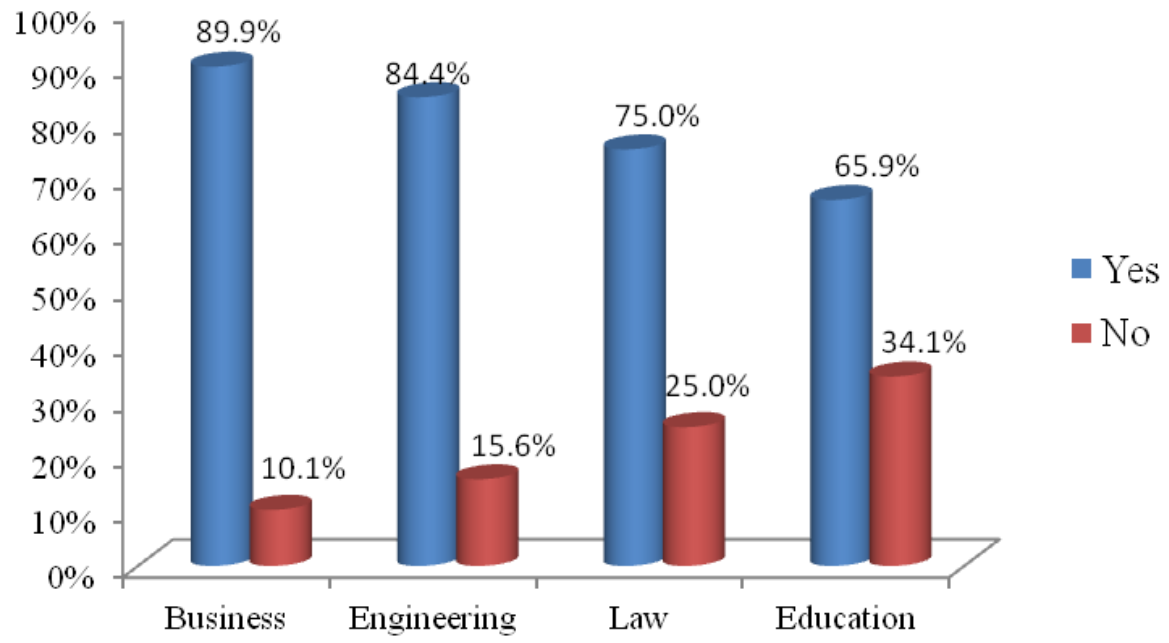

Figure 1. Differences in intentions to join respective careers across students' fields of study

Furthermore, the current study revealed that $850(81.8 \%)$ of students were highly satisfied with the degree programmes while $193(18.5 \%)$ were not satisfied with their chosen degree programmes. The data were further analysed to assess to relationship between students' level of satisfaction with their degree programmes and their intention to join their prospective careers. The results from the chi square test showed that $842(80.7 \%)$ of the satisfied students intended to join their careers upon graduation. The probability associated in the chi square statistic was below .05 , indicating a strong relationship between whether or not students intend to join their profession and their level of satisfaction with the programme $\chi 2=(3,1043)=39.7, p=.002)$.

Lastly, this study sought to determine the association between the fields of study which were hunted (chosen as a last resort) and students' decision to join them in future. The results showed that the majority of students 770 (74.2\%) were studying in the fields of their first choice while 268 (25.8\%) had just dropped into their fields by chance. The Chi square test indicated a significant relationship $\chi_{(3,1043)}=45.74, p=.01$, phi $=.36$, with a greater proportion of students $(80.1 \%)$ whose degree programmes was their first choices intended to join it than those who chose their careers as a last resort (59.7\%).

\subsection{Discussion and Conclusions}

The study found that the motivation to choose a career differed by students' fields of study. Both descriptive and content analyses showed that most students, especially in the field of education, were motivated by family factors, such as parental pressure, expectations and socio-economic status, the possibility of getting employment soon after they graduate, and lack of qualifications to join other programmes. This further denotes that for them teaching was a stepping stone towards attaining their educational pursuits. In other fields, such as business studies, engineering and law, motivational factors were basically more intrinsic than extrinsic, justifying that students in those fields knew exactly what they were choosing in relation to their interests and values. The findings of this study concur with those of Mvungi (2009) and Mkumbo (2012) in Tanzania, which demonstrated that the choice of teaching as a career is attributed to lack of qualifications to join other careers, due to the poor academic performance of both pre-service and in-service teachers. Similarly, the findings concur with previous studies by Bojuwoye and Manjwa (2006), which revealed that career choice of tertiary students is affected by the lack of finance, poor academic performance and unsatisfactory career counselling services.

Furthermore, in line with the SCCT, the study suggests that there is a significant relationship between factors which motivated students to choose their degree programmes and their intentions to join their professions in future. Students who choose their fields of study by chance were less likely to consider their future career worthwhile. For example, the majority of students who were influenced by external factors, such as loan availability, pressure from significant others and lack of qualifications, expressed dismay with their programmes and had no plans to join what they studied in future. Perhaps many students who planned to join are likely to leave soon if they find alternative 
career opportunities. This is what Super (1957) regarded as a discrepancy between aspirations and achievement, meaning that there is a mismatch between students' career interests and their choice of the fields in which they are being trained for. According to Super, this could be attributed to many factors and not limited to parental pressure and/or academic qualifications. That means, when parents negatively affect career plans of their children and if the entry requirements do not guarantee the desired choice then a discrepancy is inevitable. Psychologically, when students are constrained by external factors to choose fields they do not like, then dissonance is created between their cognition (e.g. I don't want to be a teacher) and behaviour (e.g. I have already chosen it). A person who has dissonant cognition is said to be in a state of unpleasant psychological tension, which has a negative impact on his psychological wellbeing, because the decision has already been made and things cannot go back to what they were like before (Sharma, 2012).

Generally, dissonance may affect university graduates' future work performance and commitment when employed in careers they are not interested in. Since a large group of students who experienced career indecisions were prospective teachers, it is very likely that they will have little or no motivation to teach. Thus, the stability of teaching as a profession will also be affected. It is imperative that students are advised to choose careers they are informed of and interested in rather than hunting. This will reduce the chance of experiencing dissonance, which has both short and long-term psychological effects.

The foregoing discussion shows that career choice is a process involving various factors that emerge from both the individual and the context. However, it is imperative to note that the influence partly depends on the fields of specialisation. One factor may have a significant influence on the career choice of students in one programme, while the same may not be the case in another programme. For that reason, the study concludes that whether or not students intend to join their future career is partly dependent on three factors: (a) the reasons that influenced their choice of field of study, (b) level of satisfaction with the chosen field and (c) whether or not the field was chosen by chance or was the first choice. This conclusion supports Hao's and Guzman's (2007) argument that, if students are genuinely interested in the programme they are enrolled in, they will undoubtedly enjoy what it offers, and willingly respond to all of its demands. It also concurs with Soh's (1998) remark that, unless one uncovers what motivates people to choose their careers and what makes them stay or leave their chosen professions, recruitment and retention strategies to maintain a stable workforce will never be realised. The government needs to know what university students value when choosing their professions, for example, tangible benefits such as good salary prospects, well developed infrastructure and suitable living conditions, especially in terms of what attracts people to the teaching profession. This idea goes in line with Borchert's (2002) conclusions that a clear understanding of career choice factors would give parents, educators and industry an idea about where students place most of their trust when deciding what career to pursue.

\subsection{Recommendations}

The study recommends that it is important for parents, educators and counsellors to help prospective students make an informed career decisions so as to fulfil students' career expectations. The provision of career information will make students choose rather than hunt for their career as evidenced evident in this study that $25.8 \%$ of the students found themselves pursuing degree programmes which were not of their choice due to various reasons. Furthermore, this study was delimited to pre-service students in various fields of study, future research could compare the determinants of work satisfaction, commitment and turnover intentions of employees' in various professions and localities.

\section{References}

Akomolafe, A. (2003). Relationship between fathers' occupational status and their children's occupational preference. Journal of Research in Counselling Psychology, 9, 127-131.

Bennell, P. (2004). Teacher motivation and incentives in sub-Saharan Africa and Asia. Unpublished Research Report. Retrieved from http://eldis.org/fulltext/dfidtea.pdf

Betz, N.E., \& Hackett, G. (2006). Career Self-efficacy Theory: Back to the Future. Journal of Career Assessment, 14, 3-11. http://dx.doi.org/10.1177/1069072705281347

Bojuwoye, O., \& Mbanjwa,S. (2006). Factors impacting career choice of Technikon students from previously disadvantaged school. Journal of Psychology in Africa, 1(3), 3-16.

Borchert, M. (2002). Career choice factors for high school students. A Research Paper Submitted in Partial Fulfillment of the Requirements for the Master of Science Degree. University of Wisconsin-Stout, Monemonie. 
Bojuwoye, O., \& Mbanjwa,S. (2006). Factors impacting career choice of Technikon students from previously disadvantaged school. Journal of Psychology in Africa, 1(3), 3-16.

Cosmas.V. J. (2010). Relationship between personality traits and career choice among secondary school students in Tanzania (Unpublished Master's thesis). University of Dar es Salaam, Tanzania

Creswell, J. W. (2012). Educational research: Planning, conducting and evaluating quantitative and qualitative research ( $4^{\text {th }}$ ed.). Boston: Pearson Ed. Inc.

Datu, J. A. (2012). Personality traits and parenting style as predictive factors of career choice. Academic Research International, 3(1), 118-124.

Herr, E.L., \& Crammer, A. B. (1992). Career guidance and counselling throughout the Life Span: A systematic approach. Boston: Harper Collins Publishers.

Hao, A. B \& Guzman, A. B. (2007). Why go into Teaching? Understanding Filipino Pre- service Teachers' Reasons for Entering Teacher Education: Journal of Educational Policy, 4(2), 115-135.

Isaackson, L.E. (1985). Basics of career counselling. Boston: Allyn \&Bacon, Inc.

Kidd, J. M. (2009). Career counselling. In G, Hugh \& P, Maury. (Eds.), Handbook of Career Studies, (pp.97-113). London: SAGE Publication Inc. http://dx.doi.org/10.4135/9781412976107

Lent, R. W., \& Brown, S.D. (2006). On conceptualizing and assessing social cognitive constructs in career research: A measurement guide. Journal of Career Assessment, 14(1), 12-35. http://dx.doi.org/10.1177/1069072705281364

Lent, R. W., Brown, S. D., \& Hackett, G. (1994). Towards a unified social cognitive theory of career, academic interest, choice and performance. Journal of Vocational Behaviour, 45, 79-122. http://dx.doi.org/10.1006/jvbe.1994.1027

Nwalo. K. I.N., \& Issa, A. O. (2008). Factors affecting the career choice of undergraduates in Nigerian library and information science schools. African Journal of Library, Archives \& Information Science, 18(1), 23-32

Mbilinyi, C. (2012). Determinants of career decision making among secondary school students in Tanzania (Unpublished Master's Dissertation). University of Dar es Salaam, Dar es Salaam

Mkumbo, K (2012). Teachers' commitment to, and experience of, the teaching profession in Tanzania: Findings of focus group research. International Educational Studies, 5(3), 222-227. http://dx.doi.org/10.5539/ies.v5n3p222

Mubiana, P. B. (2010). Career maturity, career knowledge, and self-knowledge among psychology honours students: An exploration study (Master Thesis), University of Pretoria, Pretoria.

Mvungi, G. (2009). School-based factors influencing students' choices of teaching science as a career: The case of government secondary schools in Ilala District (Unpublished Master's Dissertation). University of Dar es Salaam, Dar es Salaam.

Sharma, E. (2012). Change in the join choice: A matter of dissonance. International Journal of Applied Research Studies, 1(1).

Soh, K.C (1998) Who has come to teach and why? A cross-sectional comparison of four generations of teachers in Singapore. Journal of Applied Research in Education, 2(1), 19-34.

Super, D. (1957). The Psychology of Careers. New York: Harper and Brothers.

Wang, H. H. \& Fwu, B. J. (2001). Why teach? The motivation and commitment of graduate students of a teacher education program in a research university. Practical National Science Council, 11(4), 390-400.

Yu, Y. (2011). Pre-service teachers' motivations for choosing a teaching career and intention to teach in urban settings: A multi-level analysis. Dissertation submitted for partial fulfilment of the requirement for doctor of education degree, Indiana University of Pennsylvania. 